\title{
Isolated partial vaginal agenesis
}

INSERM

\section{Source}

INSERM. (1999). Orphanet: an online rare disease and orphan drug data base. Isolated partial vaginal agenesis. ORPHA:96269

Isolated partial vaginal agenesis is a rare, non-syndromic urogenital tract malformation characterized by the absence of a vagina or the presence of a vaginal dimple shorter than $5 \mathrm{~cm}$. It is often associated with uterine agenesis, hematocolpos or primary amenorrhea and dyspareunia. Ovaries and fallopian tubes are normal. 